\title{
IMPLEMENTASI TEKNOLOGI FRAMEWORK YII PADA APLIKASI BERBASIS WEB
}

\author{
Ahmad Zakir \\ Sekolah Tinggi Teknik Harapan Medan \\ Jl. HM Joni No.70A Medan 20152 Indonesia \\ suratzakir@gmail.com
}

\begin{abstract}
Abstrak - Yii merupakan Framework (kerangka kerja) PHP berbasis komponen, berkinerja tinggi untuk pengembangan aplikasi web berskala besar. Yii juga meyediakan reusability maksimum dalam pemrograman web dan mampu meningkatkan kecepatan pengembangan secara signifikan. Framework Yii merupakan salah satu dari sekian banyak framework PHP yang cukup populer dikalangan PHP developer dan merupakan salah satu dari sederetan PHP Framework yang bersifat open source yang sangat cocok untuk pengembangan aplikasi berbasis web dengan lalu lintas-tinggi, seperti portal, forum, sistem manajemen konten (CMS), sistem e-commerce dan lain-lain. Dengan menerapkan Framework Yii maka seorang programmer tidak perlu lagi membuat fungsi-fungsi dari awal, program tinggal memanggil kumpulan library atau fungsi yang sudah ada dalam framework, tentunya cara menggunakan fungsi-fungsi itu sudah ditentukan oleh framework.
\end{abstract}

Keywords - Framework PHP, Framework Yii, Pemrograman Web

\section{PENDAHULUAN}

Dengan seiring berjalannya waktu maka teknologi juga terus menurus berubah, Sebagai seorang programer web, ada banyak hal yang harus terus menerus dipelajari agar kemampuan kita selalu sesuai dengan kebutuhan pasar. Ada banyak teknologi web yang sangat populer saat dan sangat membantu para programer dalam mengembakan aplikasi berbasis web diataranya adalah teknologi framework PHP (PHP Hypertext Preprocessor).

Yii merupakan salah satu dari sekian banyak framework PHP yang cukup populer dikalangan PHP Developer, Yii adalah salah satu dari sederetan PHP Framework yang bersifat open source. Berdasarkan situs resminya, Yii adalah Framework (kerangka kerja) PHP berbasis komponen, berkinerja tinggi untuk pengembangan aplikasi web berskala besar. Yii juga meyediakan reusability maksimum dalam pemrograman web dan mampu meningkatkan kecepatan pengembangan secara signifikan.

Dengan diterapkannya teknologi framework Yii pada aplikasi berbasis web dapat membantu didalam mengembangkan semua jenis aplikasi web. Dikarenakan framework Yii sangat ringan dan dilengkapi dengan mekanisme caching yang canggih, Yii sangat cocok untuk pengembangan aplikasi dengan lalu lintas-tinggi, seperti portal, forum, sistem manajemen konten (CMS), sistem ecommerce, dan lain-lain.

\section{METODOLOGI PERANCANGAN}

Yii Framework atau lebih dikenal dengan sebutan Yii, merupakan kerangka kerja open source berbasis PHP. Pola desain yang dijalankan oleh Yii Framework mengadopsi konsep MVC (Model - View - Controller) . Berikut adalah arsitektur aplikasi web kita jika dikembangkan dengan menggunakan pola MVC (Model - View - Controller):

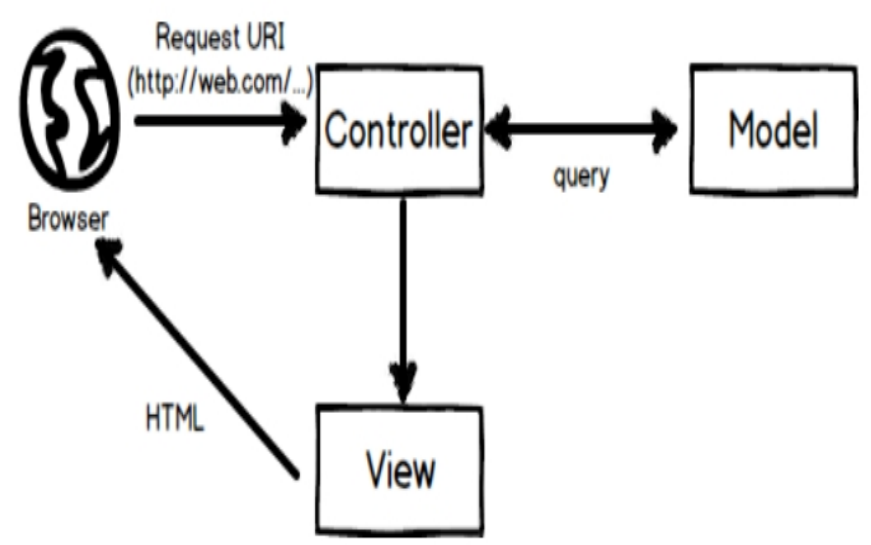

Gbr. 1 Arsitektur MVC (Model - View - Controller)

\section{A. Model View dan Controller}

Yii Framework hadir dengan konsep PHP Framework pada umumnya, yaitu dengan pola desain MVC. MVC merupakan singkatan dari Model View dan Controller. MVC merupakan sebuah pattern pemrograman yang memisahkan antara bisnis logic, data logic, dan presentation logic. Secara sederhana, MVC memisahkan antara desain, data, dan proses. Penggunaan MVC pada dasarnya digunakan untuk mempermudah pengembang aplikasi dalam mengubah suatu bagian pada aplikasi tanpa harus mengubah bagian lainnya.

Berikut ini rincian penjelasan dari Model View dan Controller yaitu: 


\section{Model}

Dalam MVC, model bertugas dalam menggambarkan suatu informasi atau data disertai dengan aturan bisnisnya. Aturan tersebut meliputi validasi, hubungan antar tabel, dan lain-lain. 2. View

View berhubungan dengan segala sesuatu yang akan di tampilkan pada end-user. Bisa berupa halaman web, rss, javascript, dan lain-lain. Dalam konsep MVC, sebisa mungkin Anda harus menghindari adanya logika pemrosesan yang di simpan dalam view.

3. Controller

Controller merupakan jembatan komunikasi antara Model dengan View. Pada Controller, Anda sebaiknya hindari kodekode yang bertugas untuk mengakses data secara langsung.

\section{B. Membuat Model}

Model menggambarkan informasi atau data beserta aturan bisnisnya seperti validasi, relasi, tipe data, dan lainlain. Ada dua jenis model, yaitu model yang disimpan dan dikumpulkan ke dalam database dan model yang setelah dipakai tidak disimpan ke dalam database. Jika kita menggunakan model yang setelah dipakai tidak disimpan ke dalam database, maka kita dapat menggunkan Form Model untuk mendefinisikannya. Sedangkan untuk model yang disimpan dan dikumpulkan ke dalam database, kita dapat menggunakan Active Record.

Berikut kumpulan semua validasi yang dapat dilakukan dengan class yang ada dari Yii Framework :

1. Boolean : validasi attribute bernilai true dan false

2. Captcha : validasi attribute harus bernilai sama dengan nilai pada captcha code

3. Compare : validasi attribute harus bernilai sama dengan attribute lain

4. Date : validasi attribute harus memiliki format tanggal

5. Email : validasi attribute harus memiliki format email

6. File : validasi attribute harus merupakan sebuah uploaded file yang valid

7. In : validasi attribute memiliki range tertentu

8. Length : validasi attribute harus memiliki panjang maksimal dan minimal tertentu

9. Numerical : validasi attribute harus merupakan sebuah angka

10. Required : validasi attribute yang tidak boleh kosong/wajib diisi

11. Type : validasi attribute harus merupakan suatu tipe tertentu

\section{Membuat View (Tampilan)}

View adalah antar muka aplikasi yang menjadi jembatan interaksi antara user dan aplikasi. Intinya view adalah tampilan yang akan dilihat oleh user. Membuat tampilan pada Yii Framework sebenarnya tidak ada bedanya dengan membuat form dengan menggunakan script HTML dan PHP, hanya saja pada Yii juga tersedia beberapa kelas pembantu untuk mempermudah membuat tampilan.

\section{Membuat Controller}

Controller adalah jembatan yang menghubungkan antara View dan Model. Controller terdiri dari action (aksi) yang akan melakukan request yang di dalamnya biasanya memerlukan Model dan View. Dengan kata lain, jika ingin membuat sebuah aksi yang bisa direquest oleh user, anda harus definisikan aksi tersebut di dalam sebuah controller.

\section{E. Perancangan Database}

Yii Framework menyediakan banyak cara untuk mempermudah anda bekerja dengan database. Mulai dari mempermudah membuat koneksi ke database, proses query, pagination, hingga meningkatkan security pada pengaksesan database. Beberapa fasilitas yang disediakan untuk mempermudah melakukan operasi database pada Yii Framework antara lain:

1. Data Access Object (DAO)

DAO menyediakan API generik yang dapat mengakses data dari Database yang berbeda. Yii DAO sendiri dibangun di atas PHP Data Objects (PDO) yang artinya jika ingin menggunakannya dalam membangun aplikasi, maka harus memastikan extension PDO untuk database tertentu sudah terinstal. Dan jika menggunakan packet server seperti wamp atau xampp, biasanya extension PDO untuk Mysql database sudah secara otomatis terinstal.

2. Query Builder

Sama seperti DAO, Query Builder juga dibangun di atas DAO. Perbedaan Query Builder dan DAO sendiri adalah cara mendefinisikan query yang berbeda. Jika pada DAO kita mendefinisikan suatu sintaks SQL secara langsung dalam suatu baris query, maka pada Query Builder kita mendefinisikan sintaks SQL secara prosedural menggunakan property dan method yang tersedia dari Yii Framework.

3. Active Record

Active Record (AR) adalah teknik populer ObjectRelational Mapping (ORM). Setiap kelas AR akan mewakili suatu tabel pada database dan propertynya mewakili attribute dari tabel tersebut. AR ini adalah model yang kita definisikan agar suatu class dapat terkoneksi ke database dan dapat membuat aturan bisnis sesuai kebutuhan database tersebut. Jadi jika menggunakan AR, kita harus mendifinisikan suatu model menggunakn AR. AR sangat membantu untuk mengurangi waktu dalam penulisan sintaks-sintaks SQL.

4. Relational Active Record

Sama dengan AR, hanya saja Active Record Relational dibuat untuk memudahkan pengelolaan pada tabel-tabel yang memiliki relasi dengan tabel lain. Untuk menggunakan AR Relational sendiri, kita harus memastikan bahwa relational datanya telah didefinisikan pada Model AR.

\section{IMPLEMENTASI DAN PEMBAHASAN}

A. Installasi

Instalasi Yii Framework yaitu degan mendownload yii framework dari website Yii, kemudian unpack file tersebut dan pindahkan pada direktori yang dapat diakses di web 
komputer anda. Lalu akses framework anda dengan memasukkan alamat berikut pada browser anda : http://localhost/namaFolderYiiFrameworkAnda/requirements/ . Maka pada browser akan tampil halaman seperti berikut :

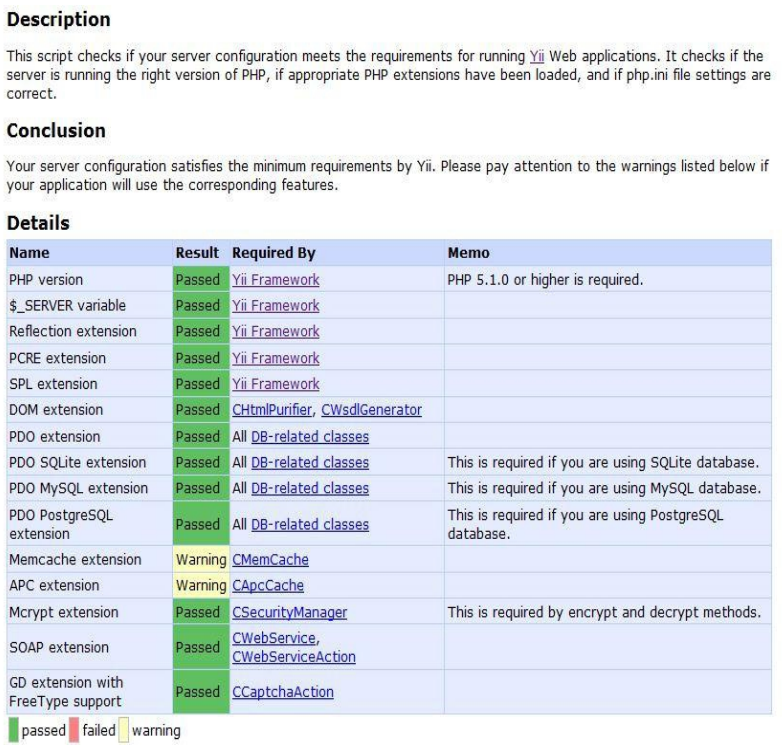

Gbr. 2 Tampilan Halaman Requirement Yii Framework

\section{B. STRUKTUR FOLDER}

Pada Yii 2 Basic, dapat langsung menemukan folder Controller, Model, dan View pada directori root. Folder assets berfungsi untuk menyimpan class Asset yang digunakan untuk mendefinisikan file css, js, dan lain-lain yang diperlukan oleh view. Folder web berisi file index aplikasi, ini merupakan folder root padawebserver (public html).

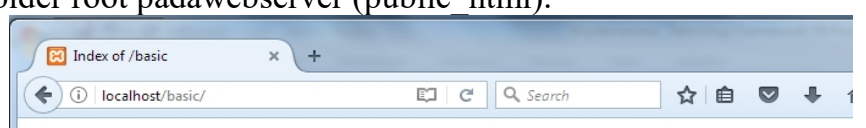

\section{Index of /basic}

\begin{tabular}{|c|c|c|}
\hline Name & Last modified & Size Description \\
\hline Parent Directory & & - \\
\hline IICENSE.ma & 06-Jun-2017 01:32 & $1.6 \mathrm{~K}$ \\
\hline assets/ & 08-Aug-2017 10:35 & - \\
\hline fodeception.yml & $06-J u n-2017 \quad 01: 32$ & 800 \\
\hline cormands/ & 08 -Aug-2017 $\quad 10: 35$ & - \\
\hline composer.json & 06-Jun-2017 01:32 & $1.7 \mathrm{~K}$ \\
\hline fomposer.10ck & 06 -Jun-2017 01:40 & $107 \mathrm{~K}$ \\
\hline config/ & 08 -Aug-2017 10:35 & - \\
\hline controllers/ & 08-Aug-2017 $\quad 10: 35$ & - \\
\hline 0 mail/ & 08 -Aug-2017 10:35 & - \\
\hline models/ & 08-Aug-2017 10:35 & - \\
\hline requirements.php & 06-Jun-2017 01:32 & $5.0 \mathrm{~K}$ \\
\hline (2untime/ & 08 -Aug-2017 10:35 & - \\
\hline 9 tests/ & 08-Aug-2017 $\quad 10: 35$ & - \\
\hline vendor/ & 08 -Aug-2017 10:35 & - \\
\hline 0 views/ & 08-Aug-2017 10:35 & - \\
\hline Web/ & 06-Jun-2017 01:32 & - \\
\hline yii & 06-Jun-2017 01:32 & 556 \\
\hline yil.bat & 06-Jun-2017 01:32 & 515 \\
\hline
\end{tabular}

Gbr. 3 Struktur Folder Yii 2 Basic

\section{YII 2 ADVANCED TEMPLATE}

Pada Yii 2 Advanced, Anda akan menemukan folder yang berbeda dengan Yii 2 Basic. Perbedaan mendasar adalah adanya folder backend dan frontend serta tidak adanya folder Controller, Model, dan View pada halaman root. Jadi pada dasarnya Yii 2 Advanced merupakan dua aplikasi yang berbeda yang memisahkan antara website public dan website administrator.

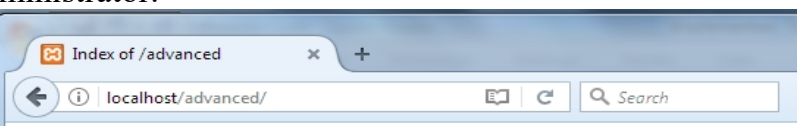

\section{Index of /advanced}

\begin{tabular}{|c|c|c|c|}
\hline Name & Last modified & Size & Description \\
\hline Parent Directory & & - & \\
\hline LICENSE.md & 06-Jun-2017 01:35 & $1.6 \mathrm{~K}$ & \\
\hline II Vagrantfile & 06-Jun-2017 01:35 & $2.4 \mathrm{~K}$ & \\
\hline Dackend/ & 08 -Aug-2017 09:36 & - & \\
\hline ?1) codeception.ym1 & 06-Jun-2017 01:35 & 167 & \\
\hline common/ & 08 -Aug-2017 09:36 & - & \\
\hline composer.json & 06-Jun-2017 01:35 & $1.2 \mathrm{~K}$ & \\
\hline composer.10ck & 06-Jun-2017 01:42 & $105 \mathrm{~K}$ & \\
\hline console/ & 08 -Aug-2017 09:36 & - & \\
\hline environments/ & $06-J u n-2017 \quad 01: 35$ & - & \\
\hline frontend/ & 08 -Aug-2017 09:36 & - & \\
\hline init & $06-J u n-2017 \quad 01: 35$ & $8.6 \mathrm{~K}$ & \\
\hline init.bat & 06-Jun-2017 01:35 & 511 & \\
\hline ? requirements.php & $06-J u n-2017 \quad 01: 35$ & $4.9 \mathrm{~K}$ & \\
\hline vagrant/ & 08 -Aug-2017 09:36 & - & \\
\hline vendor/ & 08 -Aug-2017 09:36 & - & \\
\hline yii.bat & 06-Jun-2017 01:35 & 515 & \\
\hline
\end{tabular}

Gbr. 4 Struktur Folder Yii 2 Advanced

\section{MENJALANKAN YII 2 BASIC}

Sebelum memulai menjalankannya, pastikan telah menginstal Yii 2 Basic Template pada folder htdocs. Kemudian buka browser dan ketik http://localhost/basic/web.

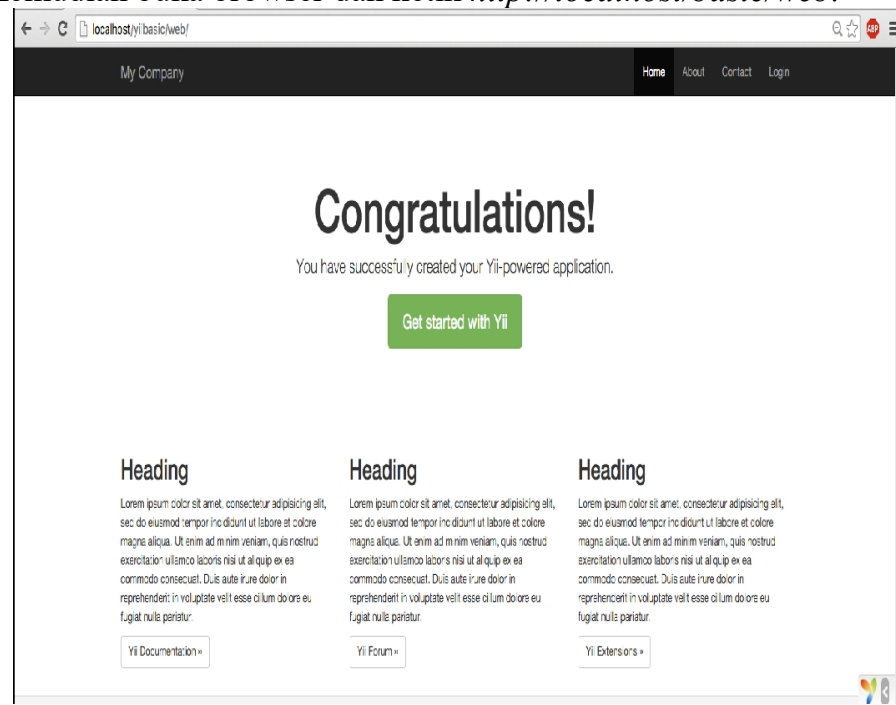

Gbr. 5 Tampilan Yii 2 Basic 


\section{E. MENJALANKAN YII 2 ADVANCED}

Pada Yii 2 Advanced memiliki sedikit perbedaan dalam tatacara penggunaan awal. Yaitu harus mendefinisikan terlebih dahulu environment aplikasi, Apakah Development atau Production. Sebelum memulai menjalankannya, pastikan telah menginstal Yii 2 advaced Template pada folder htdocs. Kemudian buka browser dan ketik http://localhost/advance/web.

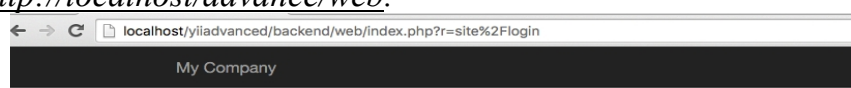

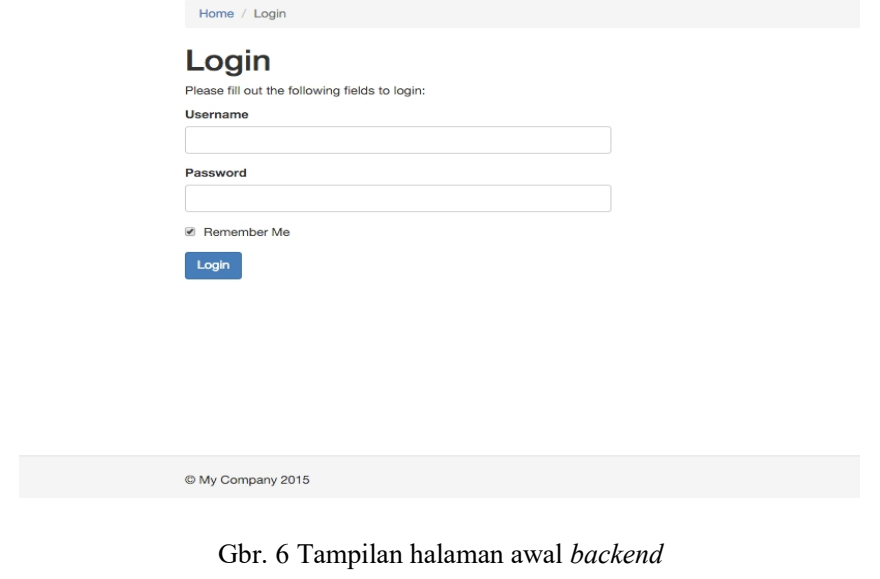

Buka halaman front end dengan masuk ke link http://localhost/advanced/frontend/web maka akan muncul tampilan halaman Front end

\section{KESIMPULAN}

Yii merupakan component based high performance PHP kerangka kerja untuk mengembangkan skala besar aplikasi Web. Yii ditulis dalam OOP dan dilengkapi dengan referensi kelas menyeluruh dan tutorial yang komprehensif. Dari MVC, DAO / ActiveRecord, widget, caching, RBAC hirarkis, layanan Web, untuk tema, I18N dan L10N, Yii menyediakan hampir semua fitur yang dibutuhkan oleh saat ini pengembangan aplikasi Web 2.0. dan tidak banyak kekurangan yang ditemui pada penggunaan Yii. Yii adalah salah satu framework yang sangat ringan dan dilengkapi dengan solusi caching yang memuaskan, mencakup segala macam fitur-fitur yang diperlukan dalam membangun sebuah web. Namun, bukan berarti Yii tidak mempunyai kekurangan. Salah satu kekurangan Yii yang cukup signifikan adalah tidak compatible nya Yii dengan PHP 4.

\section{UCAPAN TERIMA KASIH}

Dengan terselesaikannya tulisan ini, penulis mengucapkan terimakasih yang sedalam-dalamnya kepada :

1. Allah S.W.T. atas limpahan karunia dan hidayahnya sehingga penulis dapat melaksanakan penelitian dan menyelesaikan tulisan ini.

2. Kedua Orang Tua, Istri dan anak-anak saya yang telah membantu dan mendukung saya dalam mengerjakan tulisan ini.

3. Seluruh tim InfoTekjar (Informatika dan Teknologi Jaringan) Universitas Islam Sumatera Utara di dalam penerbiatan tulisan ini.

4. Seluruh Civitas Akademika Sekolah Tinggi Teknik Harapan Medan atas kerjasamanya selama penulis melakukan penelitian.

\section{REFERENSI}

[1] Caldarelli, F., (2015). Yii2 By Example: Packt Publishing Ltd.

[2] Pescarin, P., (2015). Learning Yii Testing: Packt Publishing Ltd.

[3] Sharive, (2013). Yii Framework: Menguasai Framework PHP Terbaik: Loko Media

[4] Sharive, (2014). Yii Framework: Proyek Membangun Website dengan Yii Framework: Loko Media

[5] http://www.yiiframework.com tanggal akses 25 juli 2017

[6] https://www.scribd.com/doc/52982287/PENGERTIANFRAMEWORK tanggal akses 25 juli 2017

[7] http://php.net/manual/en/intro-whatis.php tanggal akses 01 gustus 2017 